\title{
[RE-]DISCOVER THE CITY
}

\author{
J. Saniya* \\ Institute for Art and Culture, Lahore
}

\begin{abstract}
:
"I am a camera."

First line of Berlin Stories, Christopher Isherwoods

Cities transcend familiar rhythms; they are neither conservative nor modern - rather; they are both. Urban subjectivity is a reaction to being exposed to difference and complexity which divides perception. With this research, I would like to address the urban account of interiority within the city; the subjective feeling linked to an exterior condition, the issue of the inside-outside divide that is made by the street rather than removed from it. This is between the enclosure of a physical space, inner and the subjective, outer and the more physical, the self and the city; and the ambiguous interior-exterior boundaries of its citizens.
\end{abstract}

According to Richard Sennet, a sociologist, identity can be defined as the image that people have of you and that you may have of yourself that comes of constant interchange of yourself with your surroundings. Where is this more dynamic, complex form of identity found in the city? In order to get an in depth understanding of the urban field I will dwell into the exact agents/ players that constitute it. Using a psychogeographic approach, this project will understand the space and the constructs that form when a person interacts, enters, demarcates and starts forming enclosures both physical and nonphysical.

Keywords: Interiority; Urban Subjectivity

\section{Introduction -The City as Observation}

\section{But I feel grand. Yes I think that's how I feel. I feel grand and magnanimous.}

I believe that a city manifests itself in relation to the cultures and values of the society and finds itself between the dialectic of influencing and being influenced by its people and society. Modes of representation, such as photography, often frequently recall familiar fictional representations of the city or inspire narrative flights of fancy rather than being factual depictions of urban experience; this itself being a key trait of urban literature. In my work, I attempt to capture these fleets of familiarity as an onlooker in the myriad of spaces that exist in an urban landscape.

Making the city observable has been an ongoing project. I begin this paper by giving an overview of the various factors that led to this research and instigated me to begin this work. From early experiences to research projects that focused more on text than images, the city always remained centerfold throughout. I intend to primarily subvert the traditional ideas of a city. This research has focused on the mere existence and meaning of real and metaphorical spaces and how they shape or influence the individual and collective identity of its people. My key query here revolves around what defines the inherent nature of a city and how much of a role does it play in the lives of its inhabitants. Are cities ever real? Can cities be unreal? Where is the border between reality and perception? Should cities be treated as a linear or fixed entities? 


\section{The City as a Fact}

Welcome to the City

We are all migrants native to the universe.

I moved to Lahore on my own in the beginning of 2017 in search of identity. I began to look at the city as an organic, continuously growing organism and the tangible-intangible cultures as the means of differentiation, with theory being not universal but within a context. I had moved not cities, but entire continents during my early years.

Why, you may ask. Why continents? Which continents?

My father moved to Dubai in the late 1960s. The city was just beginning to boom and he was young, energetic and ambitious. He lived there for the next forty years, watching it grow into a place that is now more than just a desert. In the summer of 2005, during our annual trip to my grandparents' house in Rawalpindi (Pakistan), he was called by the UAE intelligence and asked to not return. He had been branded with having terrorist connections with a Shia (an Islamic Sect) group in Iran. His family could return, the man said and I clearly remember, but we are not responsible for where you may be taken if you are found on our soils.

What soils, one may ironically ask. Aren’t you all desert sand?

My mother went back; my younger brother and I were left at my grandmothers. She enquired into government offices, was shunned away by all, and even threatened by some to back down. Eventually, despondent and utterly confused, she packed up our house to return back to us in Rawalpindi and began to rebuild.

This was the beginning of the silent accusatory deportations of Shias by the majorly Sunni (another Islamic sect) Government of the UAE. We began to hear, over the years, of other family friends and acquaintances going through the same. Some were left jobless and desperate, the others were just asked to leave of no firm grounds. I went back to my city of birth after ten years. The seemingly familiar city, once again, made me feel alienated.

The following year, my father's first cousin, an eminent ENT specialist from Karachi, was shot in his own car, on his way back home from the hospital. His family began receiving threats and was forced to flee to the United States. Other families were broken apart, I was almost becoming immune to blast news alerts and shrinking households. My first cousin, another successful banker from Karachi, was targeted several times, along with constant threats to his family. He was forced to move overnight to a city he thought safer, Rawalpindi. I resided here with my family at that time. I began noticing pockets forming and the urban landscape shifting. Everyone and anyone who was a Shia Muslim began to move into houses closer together. In this unplanned city, Imambargahs sprung up in the middle of neighborhoods, followed by other Shia dominated households around it. We now felt safer.

In November 2013, gunmen stationed at a Sunni seminary opened fire on a Shia Muslim religious procession. The Shia mourners were marking Ashura, an annual day of lamentation to mark the death of Imam Hussein, a grandson of the Prophet Mohammad. An army unit based in Rawalpindi eventually reached the scene and took control. A curfew was imposed over the city and mobile networks were suspended.

My father, brother, uncles and male cousins were all in the procession. This was the second time I was violently reminded of the sect that I was born into and I, once again, lost my sense of belonging to yet another city. For 
hours, my mother and I switched across news channels, impatiently looking for some update of our loved ones. We were desperately trying to get in touch with any one of them, with no luck.

The next morning, they all came back home, half wounded and dripping in blood.

I was finally jostled awake from my numbness when, the following year, my father and brother were at the local Imambargah (religious sanctuary) for evening prayers in Ramadan and a suicide bomber attempted to enter into the premises. I remember the windows of our house shattering at the sound of the blast and me running to my mother. We both knew what had happened when we looked into each other's eyes. My brother was hospitalized for days and we were shaken. We thought our neighborhood was safe, didn't we? We were all primarily the same sect, everyone knew each other. Any of our neighbors who weren't Shia weren't exactly against us in any way. There were suspicions in the air, confessions of love and friendship - death had felt closer this time. This time the city felt unsafe and even more unfamiliar.

I can list an entire page of targeted events, with real figures, charts and graphs, but this is too personal an experience for news events and media reports. Being targeted by a gun was becoming everyday news from my cousins in Karachi. But they lived in apparent safe pockets too, didn't they?

Around this time, I moved to Lahore to commence work at the Institute of Art and Culture, which was, at the time, setting up curriculums and attempting to acquire a charter. I was now in a new city; a new urban landscape, a crowd of very different people, a whole lot more brooding environment. I did work that probed themes of space, memory, familiarity, our interaction with the everyday and used photography to document the formation of any space - sacred and not.

I mention 'sacred', because I began a struggle to understand the belief system that I had been born into, why something as sacred as individual belief was attacked and how much of a city lended to its inhabitants individual identities. The old part of Lahore was primarily Shia, with bigger and tougher pockets of Shia communities that had traditions of pre partition Imambargahs and even older families residing around them. These spaces were old enough to have become mythologized into centuries old worship areas. In the subcontinent, mazaars and other such sacred spaces implicate the idea of offering a similar glimpse into a chance encounter with holiness that seems so unreachable for the normal man.

In the summer of 2016, a derive along the streets of Garhi Shahu in Lahore led me to come across the primarily Shia Mazaar of Bibiyaan Pak Daaman by accident. I came to question and delve deeper into the ideas of a sacred space and what made it so for its people. I spent nights and days there, in turn observing my own sect from the view of a non-practicing outsider. The area around the mazaar was inhabited by Shia families that clustered closer in protection of the sacred space and of each other, barricaded with police barriers at every entrance. This led to a research paper at the THAAP Conference in Lahore in 2016. 

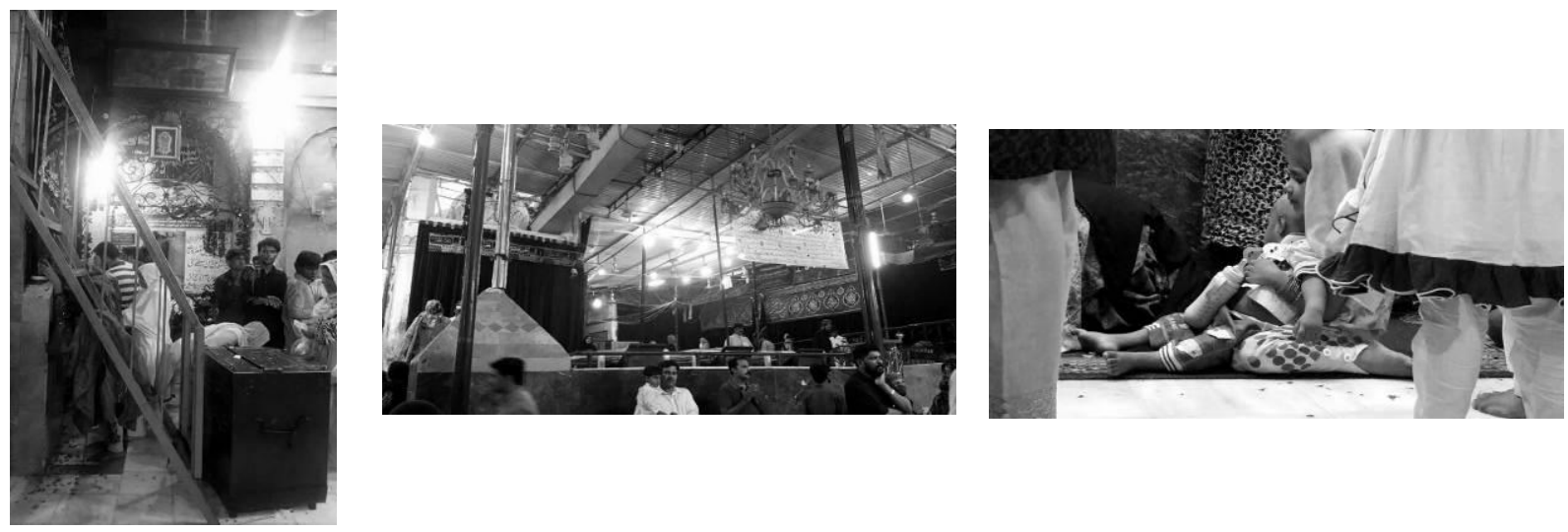

Figure 1: Images of the interior of the Shrine

Based primarily on personal reflections and internal experiences, I delved deeper into the phenomenological aspects of its urban fabric through a process of introspection and propensity, the idea of religious experience itself with reference to Carl Yung, supported by Arthur W. Franks concept of socio-narratological analysis, an interrelation between the narratives of the people that create its essence alongside the social structure of the rituals that rhetorically configure the inherent edifice of the space.

This project filled me with an ontological desire, to perceptually re-evaluate the concept of what a city was in itself; produced and reproduced by people always in a state of flux and changing forces - experiences absorbed by its people, involving countless events led by various acts and supported by multiple behaviors. [re-]discover The City is an ongoing studio-led research project with photography as my tool to understand and visually represent my ideas of urban unheimlichkeit. At some points, I will leave you with more questions than answers, more misperceptions than clarities but hopefully, more revelations than stagnancies.

\section{The City as a Stage}

"The scenes that illustrate this book are all about us. For illustrations, please look closely at real cities. While you are looking, you might as well also listen, linger and think about what you see."

-Jane Jacob (Jacobs)

The lines above are an epigraph to Jane Jacobs, 'The Death and Life of Great American Cities', published in 1961. It establishes an attentive way of looking at the city by use of methods that could represent, and in many ways instigate social encounters in the city via complex formal vocabularies, unconventional methods of presentation and direct engagement with the social fabric.

I became the City Organizer of Lahore for Jane's Walk in 2016, a movement of citizen led walking tours inspired by the urban activist Jane Jacobs towards community-based city building. As a result, Lahore became part of a fantastic global festival of Jane's Walk in the first week of May, 2016. Prior to this, I organized a Jane's Walk also on the historically rich Main Boulevard Road in Gulberg, Lahore, focusing in particular on the various designs and typologies used on the entrance gates of the houses, ending with discussions on the present identity and the critical future of these dwellings in the midst of a rapidly growing urban jungle. 


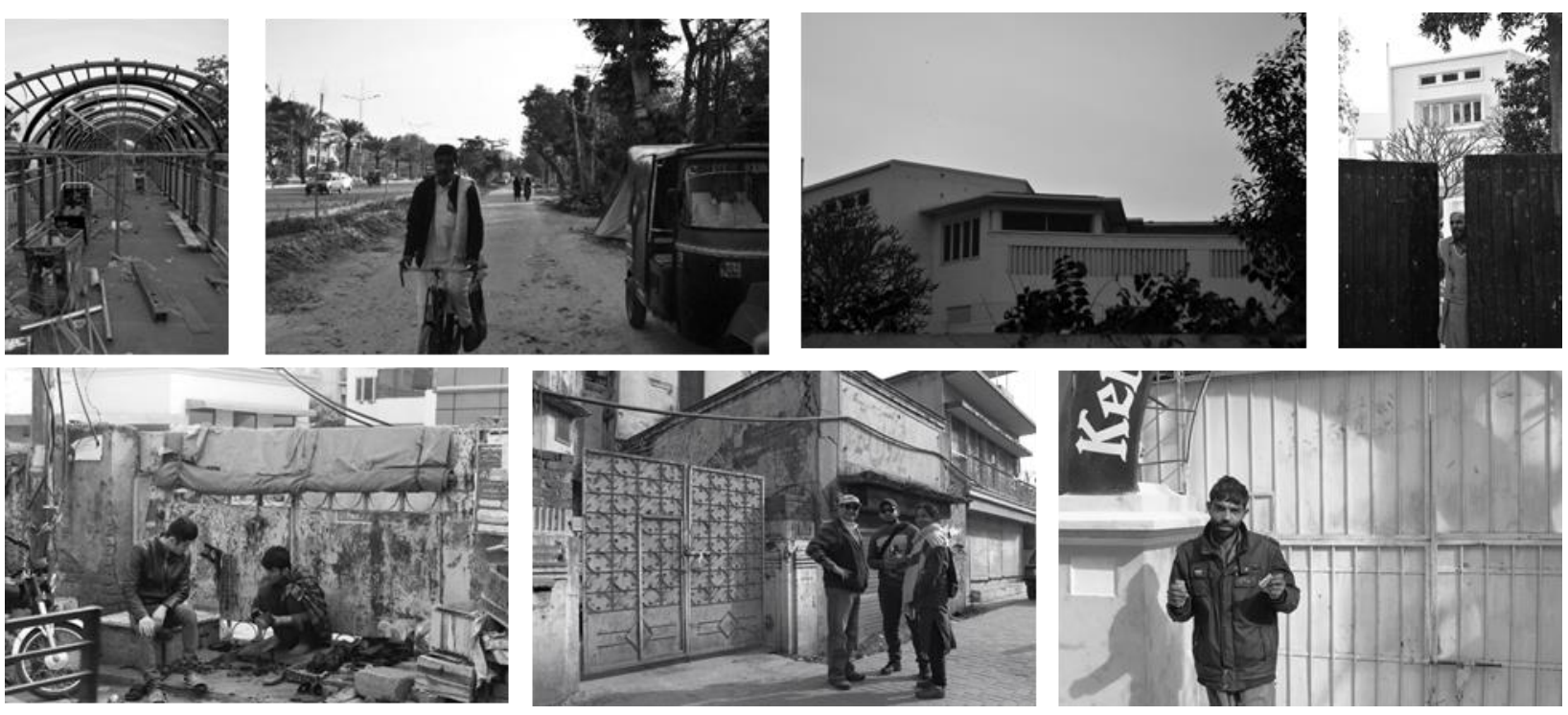

Figure 2: Derive on Murree Road, Rawalpindi

Another ambitious Derive Project on the archaic Murree Road in Rawalpindi was a lustrous experience of storytelling as people from different disciplines joined to not just take photographs but share personal narratives along the endless acres of concrete that served as their backdrops. This was followed by an exciting and interactive session with the participants making mental maps of their routes, keeping the ideas of the Situationists in mind.
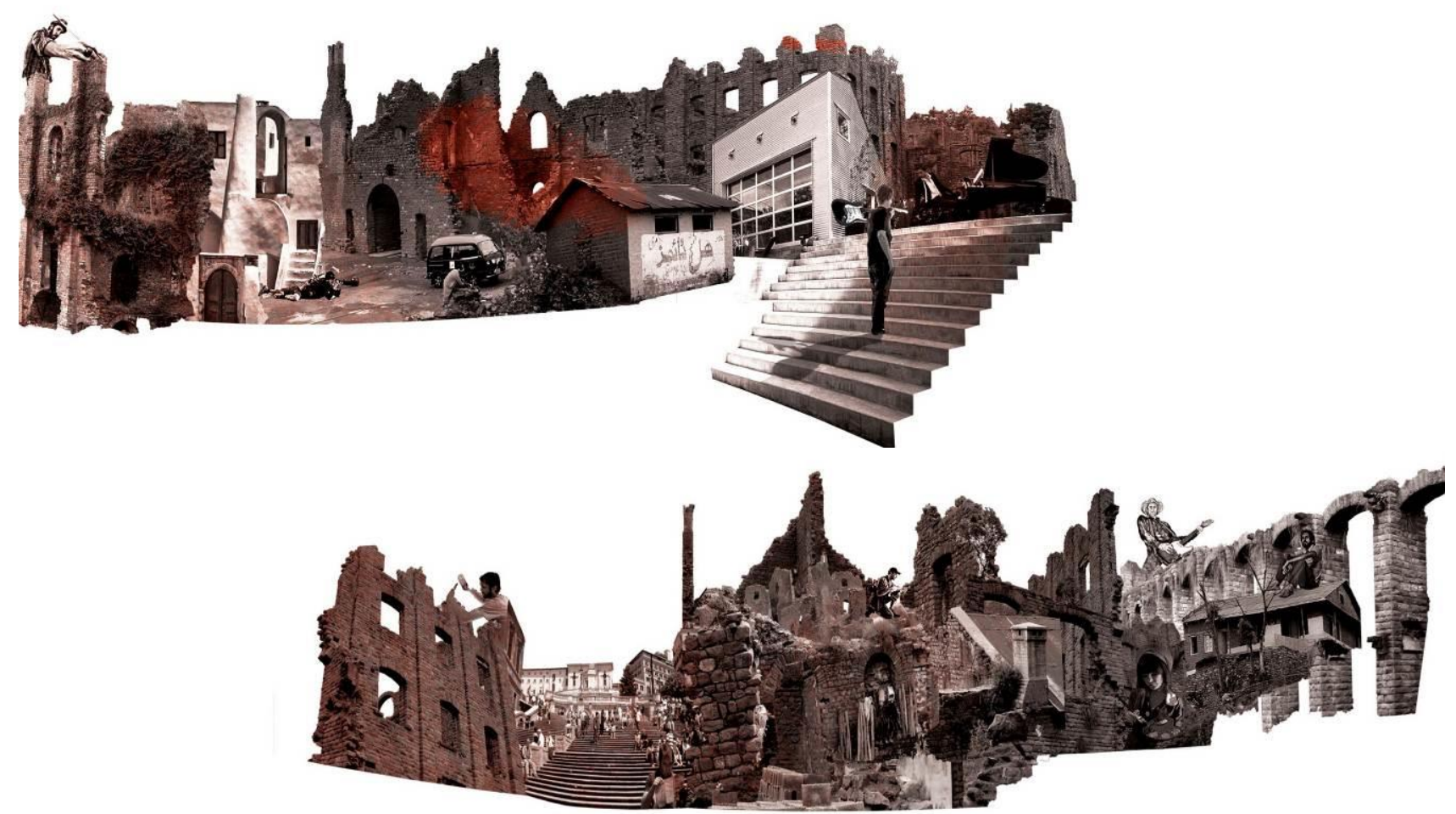

Figure 3: Result of the Murree Brewery City Walk

A 'City Walk' along the ruins of Murree Brewery Factory in Ghorra Gali, Murree, tantalized the participants with the glorious history of its crumbling walls. These walks were a major driving force for me as they got 
together people from several walk of life; there were engineers, doctors, $\mathrm{PhD}$ scholars from humanities among other architect and artist friends. It was interesting to see how they got together, had progressive conversations and resolved issues as a group of citizens with one underlying similarity - the city. It helped them discover their city from a new perspective and thus, in the vibrations, the city rendered itself available to both the pedestrian and the scholar.

Another intervention was a part of the workshop conducted by the Social Innovation Lab at the Lahore University of Management Sciences (LUMS) on Human Centered Design. This workshop aimed to help strengthen my winning design of 'Intersections', a bus stop design competition for the Lahore Transport Company, organized by the Lahore Biennale Foundation, Parks and Horticultural Authority and Lahore Commissioner's Office.

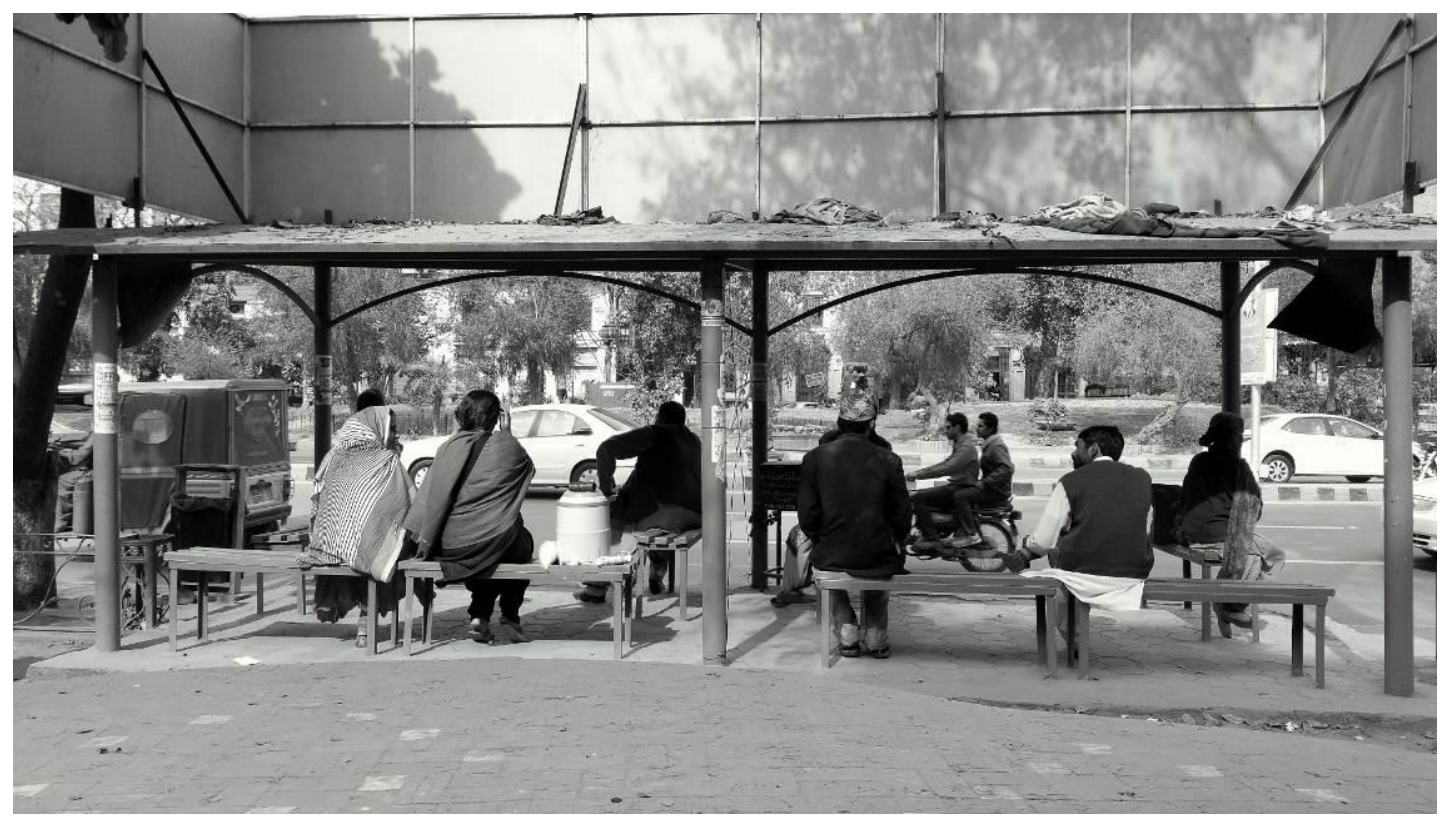

Figure 4: Bus Stop on Mall Road, Lahore

An individual result of the workshop was a social study of the existing bus stops in the city of Lahore, using inductive and deductive research techniques with tested and implemented prototypes. The existing stop was divided into male and female sections, basic amenities such as clean drinking water and internet provided, and three waiting male actors and two waiting female actors planted into the stop to interact with the general public. The frequent users of the bus stop were also asked to draw sketches of their routes every day from home to the office and back.

Erving Goffman says and I state, "I shall consider the way in which the individual in ordinary work situations presents himself and his activity to others, the ways in which he guides and controls the impressions they form of him, and the kinds of things he may and may not do while sustaining his performance before them." (Goffman). 

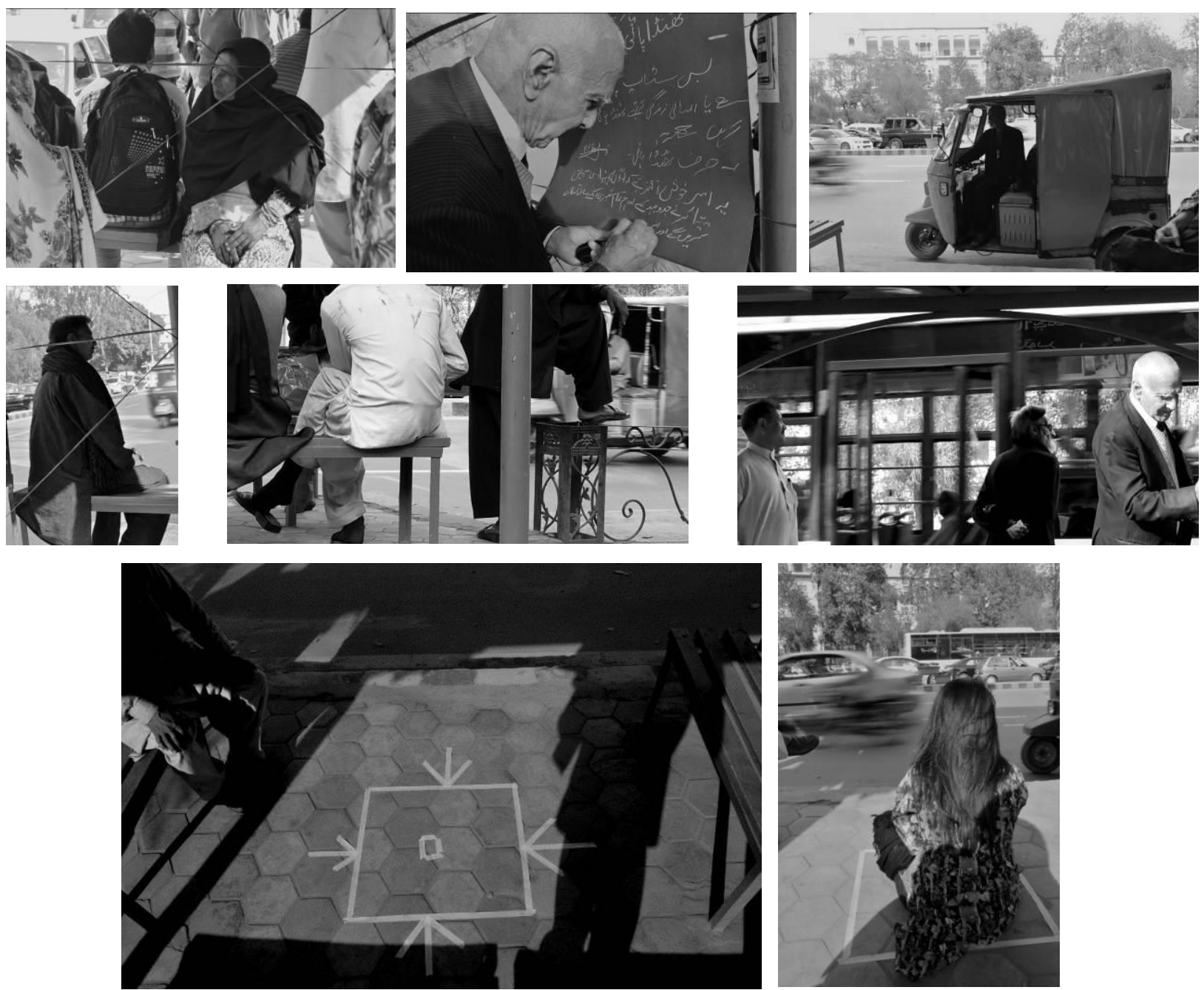

Figure 5: Intervention at the Bus Stop

As part of the intervention, a square was traced on the ground in the far left of the stop area marked males. I, a female, sat in the square in the midst of surrounding males, during the 16 hours of documentation to note the reactions of the surrounding people and passerby. This was to understand the theme of human behavior in a social situation that makes them uncomfortable as per societal rules and the way that the subject appeared to others. This project was a provocative intervention into the different classes of Lahore using the bus stop as a staged theatre, with props and characters, participants hacking the urban space, a backstage, right offstage and left offstage. 

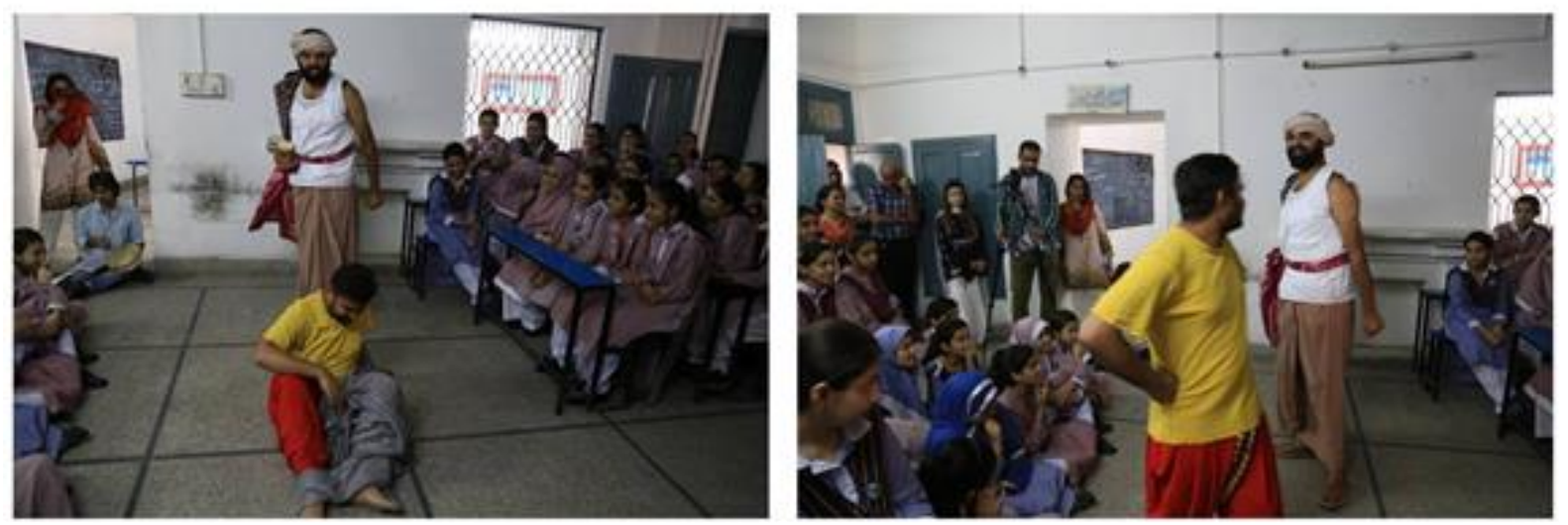

Figure 6: Jamoora Madaari Performance

My time at the Institute for Art and Culture has given me the opportunity to keep running my research with university collaborate projects. One such project was the International Day of Monuments and Sites (ICOMOS) on $18^{\text {th }}$ April and $19^{\text {th }}$ April 2017. I organized the first part of the ICOMOS event at the Najaf Ideal Girls High School, Mochi Gate branch in Androon (old) Lahore, for which I researched on the history of the Gate and incorporated it into a script for a short performance titled 'Jamoora Madaari: Mochi Gate ki Kahaani'. Prepared using the traditional story telling technique of folk theatre, jamoora is generally a performer who plays a specific type of sidekick role, complying with every command given by his master, the madaari in this case, often with restrained deviations to make satirical points or create a comical effect. This particular technique was used to familiarize the young crowd to yet another dying culture of Pakistani theatre, enacted in their local language Punjabi. The performers indulged the girls with accounts of the oldest origins of their locality, that date back to 1575-1581 when the Gate was built by the Mughal Emperor Akbar and recorded as 'Morcha Darwaza'. They also spoke about the streets that the girls were themselves residents of, such as Mohalla TeerGaran (area of arrow craftsmen) and Mohallah Kaman-Garan (area of bow craftsmen), originally named to distinguish various specialists manufacturing equipment for the army, especially the cavalry. In between humorous swaps, the audience was given an account of the historical and political significance of their 'Bagh baroon Mochi Darwaza' : 'Speakers Corner' (the Mochi Bagh) and they were given the chance to rediscover their ancestral space. (Jafri)
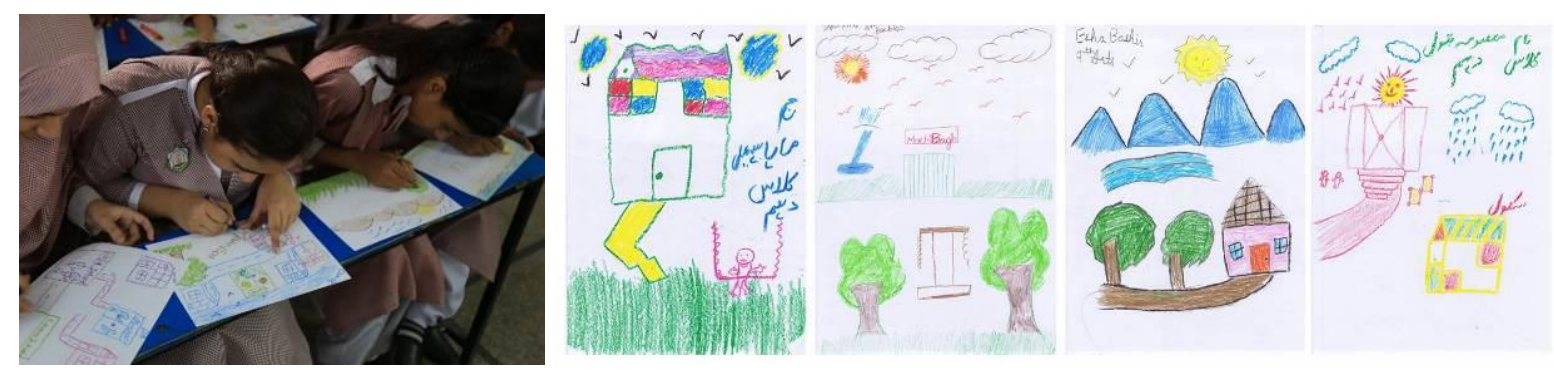

Figure 7: Drawing Exercise

This was followed by a Drawing Activity whereby the girls were given blank sheets of paper with color pencils and asked to sketch the experience of their route from home to school. After a fun-filled interactive session, it was understood that if encouraged to make native marks (draw in their own way), and experiment with colors and imagination, most of the students grew less doubtful of their ability to draw and began to thoroughly enjoy the process, which is a very essential part of drawing itself. Our team personally interacted with the students as they animatedly related stories of their everyday routes, that mostly ranged from five to ten minute walks with either a parent or an older sibling if not alone. The result was an array of creative and imaginative sketches of 
important landmarks within the Mochi Gate Area. Recurring themes were kiosks with displays of assorted goodies and spices (Golden Kiryaana Store had Surkh Mirch and Kaali Mirch), a noteworthy mosque of the area (Jamia-e-Masjid), intricate details of doors and windows characteristic of the architecture of Old Lahore, Mochi Bagh with swings and vegetation, food kiosks such the Halwa Poori Wala, Doodh Waala (Milkman) and the oldest and most significant bakeries of Mochi Gate, Kashmir Bakers and Rafiq Sweets (added tagline under its header: Anything you Want!).
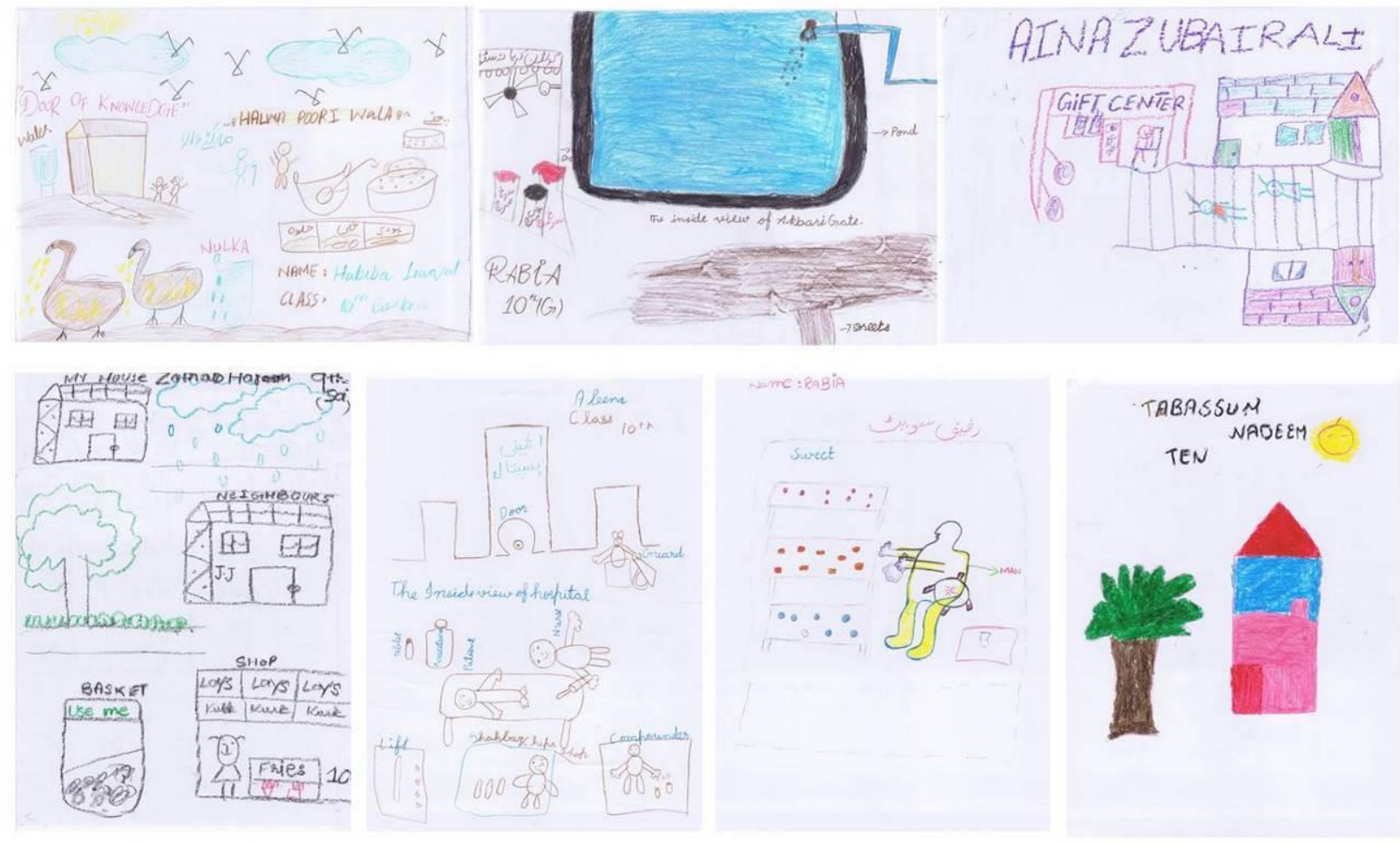

Figure 8: Some more Drawings

One girl gave us a complete inside view of the nearby hospital with various stick men tagged as a guard, nurse, patient with paracetamol and other tablets on a nearby table and a compounder travelling down a lift. There were sketches of nearby areas such as the Akbari Gate, doors of neighbors with their initials and interesting additions such as the local tomb with candles burning, sometimes as fascinating 3D perspectives and sectional elevations. This activity made us question yet again the idea of local monuments that act as historical anchors of any particular area such as the recurring Khalifa Bakers in the sketches.

All cities have layers upon layers of associations and claims of tradition and culture that become a significant part of its inhabitants. Personal experiences often prescribe their cities with associated and diverse values that can range from being communal to being individual. But as the question arose when we discussed our results later, can perhaps the Khalifa Bakers, Rafiq Sweets or the small tomb achieve the status of local significance? Is their city similar to mine? Do we share the same or do we classify as different despite of being within the same city of Lahore? (Jafri)

\section{The City as a Generic City}

"When we refer to the city in the late $20^{\text {th }}$ century, we talk in numbers we can't comprehend, and about sizes we can't visualize. The contents of making a city observable are meant to demonstrate how information about cities could be made understandable to everyone, from city administrators to urban planners to everyday citizens."

- Richard Saul Wurman (Wurman) 
In 1952, Bons Yakovlev released the movie, Chicago Morning, the city of Chicago catalogued waking up from 4:30 to 9:30 in the morning. 11 unnamed students from the Institute of Design were asked to photograph the morning of Wednesday, April 16, 1952. Yakovlev was interested primarily in the role of the camera as a tool for exploration and research. Hence, whatever the students found and bought back drove the makeup of the film itself. It was a way to think about the city, to discover something about the city that perhaps they hadn't thought about before. (Beste)

My photographic practice constantly asks the very significant question of whether or not an image can count as observable and what forms of visualization are best suited to addressing the city as sometimes a scene of crisis and at other times, a scene of celebration; an exploration of how the person balances a human existence with the demands of the city. [re-]discover The City aims to work with this urban subjectivity of the city as a means of representation. As the silent observer, the casual flaneur on a leisurely walk, scenes are captured from randomly picked sites within the city.

This project is divided into the three main concerns, Walking Around People, Walking Around Places and Walking Around Things. This research examines interactions amongst people, places and things; the inter relationship between the physical and emotive, the interior evoking a sensation very different from exterior spaces, the chance encounters and the brushes with human difference; the citizens of the city as the main actors of this documentation.

Repetition is deployed to introduce duration, chance and to give an appearance of movement and vibration. As Kevin Lynch famously stated, "The experience of a city is basically a moving view, and this is the view we must understand if we wish to reform the look of our cities." (Lynch) The city lent itself as a set to be photographed, or at the very least, to be seen photographically. Rather than an object of visual inquiry, then, the city in this scenario became a moving image to be seen.

In this work, there is an obscurity. Almost like a portal, a window as in one of Elena Guros paintings, the atmosphere of the city seems somehow to loom larger than the context inside the window; a barrier between the viewer and the information. The photographer is always looking straight towards or down into the personal space. The presence of a human vantage point is intentional; the viewer is always present as the audience, rediscovering the surroundings in a subtle way, but not in direct confrontation with the subject. The conscious sense of personal space within personal space, personal space within public space and familiarity between subjects is also constantly being redefined. The light is always just enough to indicate the presence of a person, but not enough to define details. Body language is significant, intimate situations always underlie with a sense of non-judgment and acceptance. People are walking, standing, sitting, going, waiting, being, watching, talking; with rapid movement and negative dissociation between them and the power of the city in a montage like presence. Hence the images are often set in relation to each other, thought in extension, or as part of a larger set of images.

Text also plays a very important role in the work. From a childhood surrounded with slogans of shia flagellations of mourning, the visual presence of text has always been a part of my work: the relationship of text with the image, the text upon the image, the image with the text, the image upon the text, the text with the negative space around it and the negative space with the text around it. The image exists as a visual statement, as the text also dissolves into form. This play of language cannot be more succinctly described than Edward Ruscha, "words are pattern-like, and in their horizontality they answer my investigation into landscape. They're almost not words - they are objects that become words." (From Picasso to Ed Rusha: the use of text in visual art explained) 

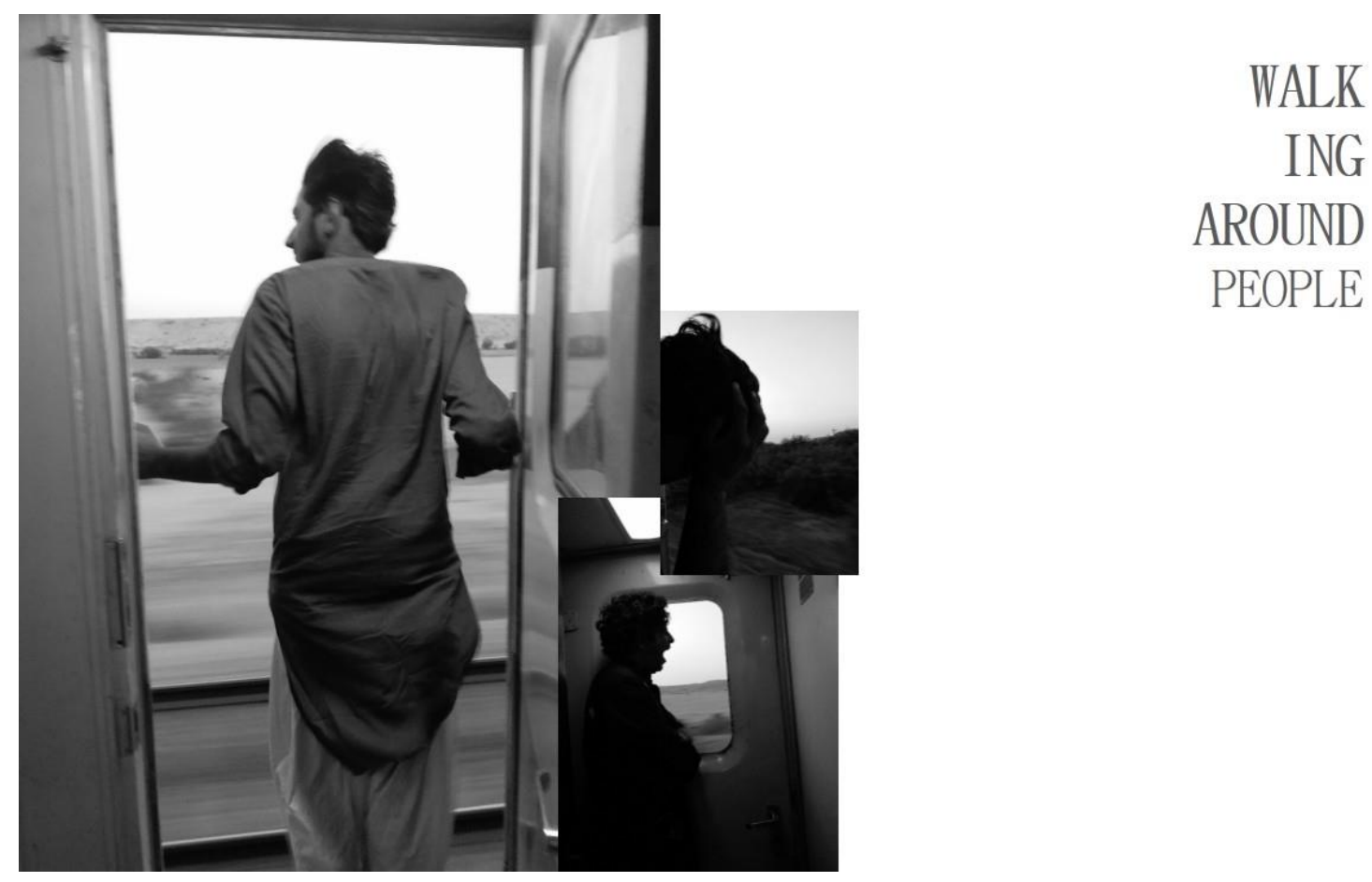

Descriptive Theory of the Essence of Pure Experiences

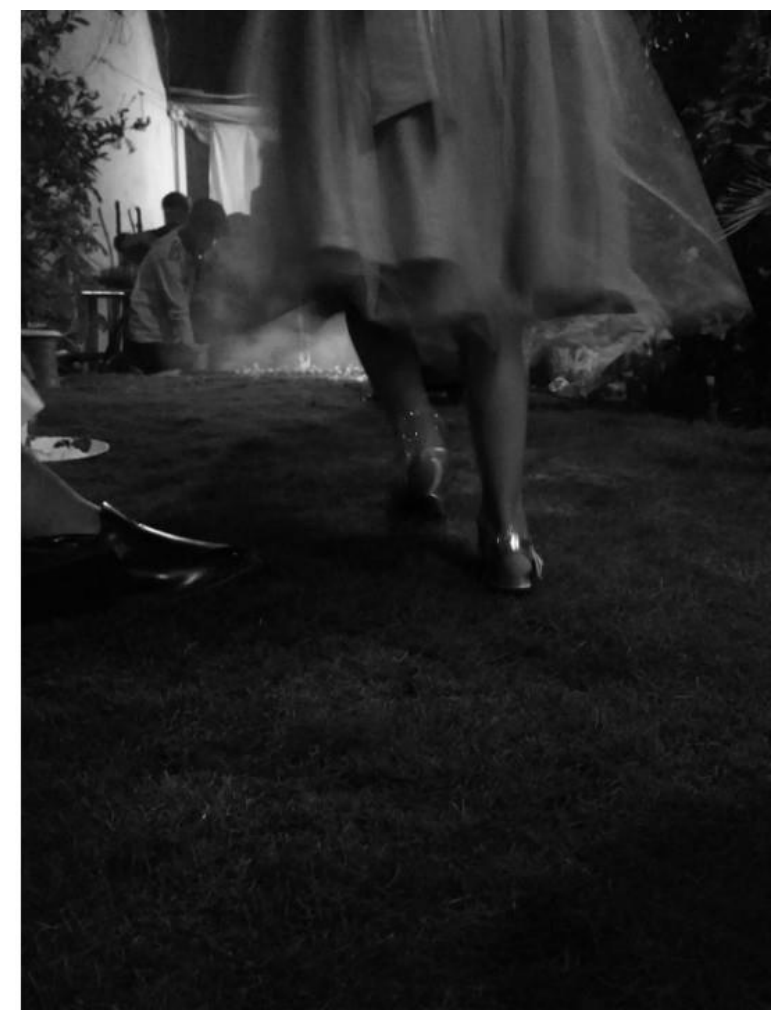




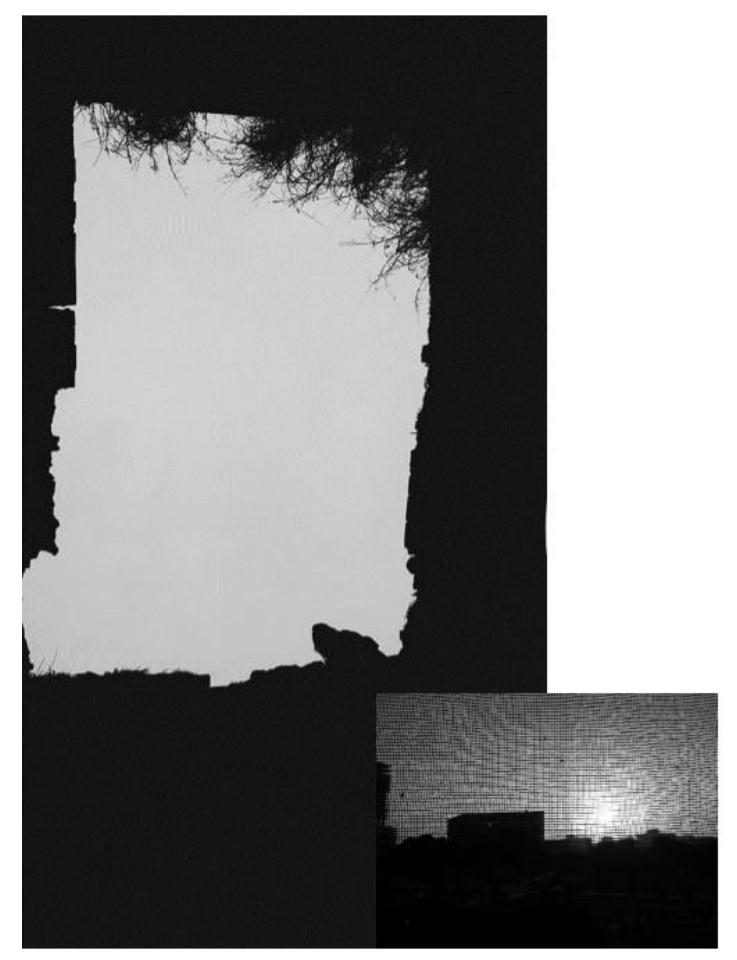

\section{WALK ING AROUND PLACES}

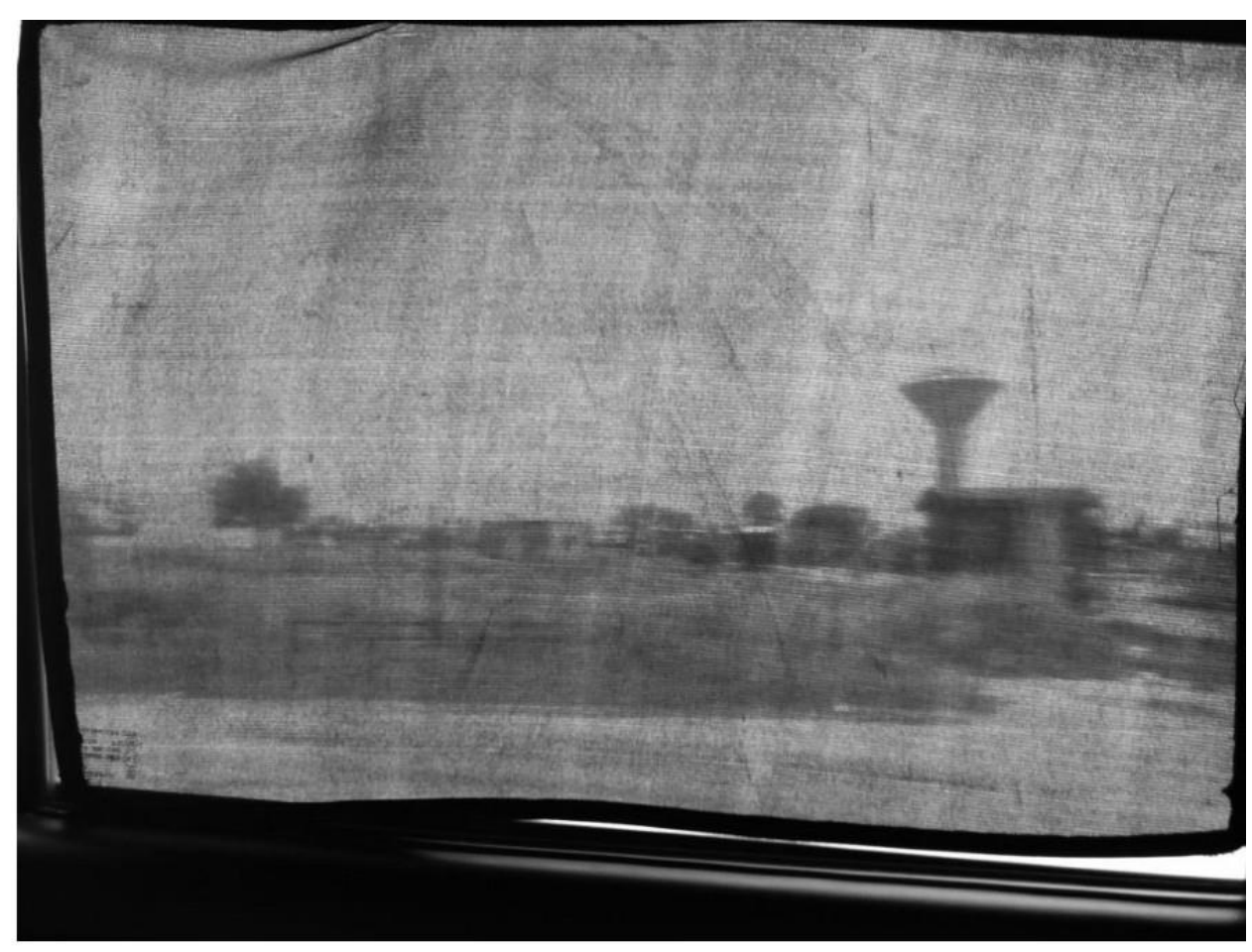

Absurdity of a World Outside Our Own 
Proceeding of the $5^{\text {th }}$ International Conference on Arts and Humanities, Vol. 5, 2018, pp. 35-49

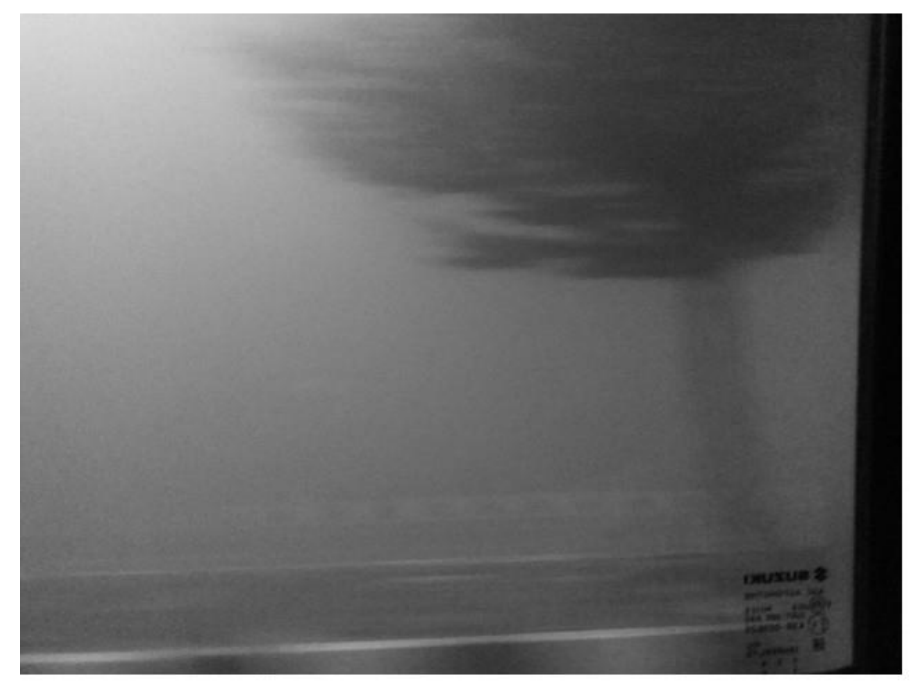

Abstract Phase of Experience

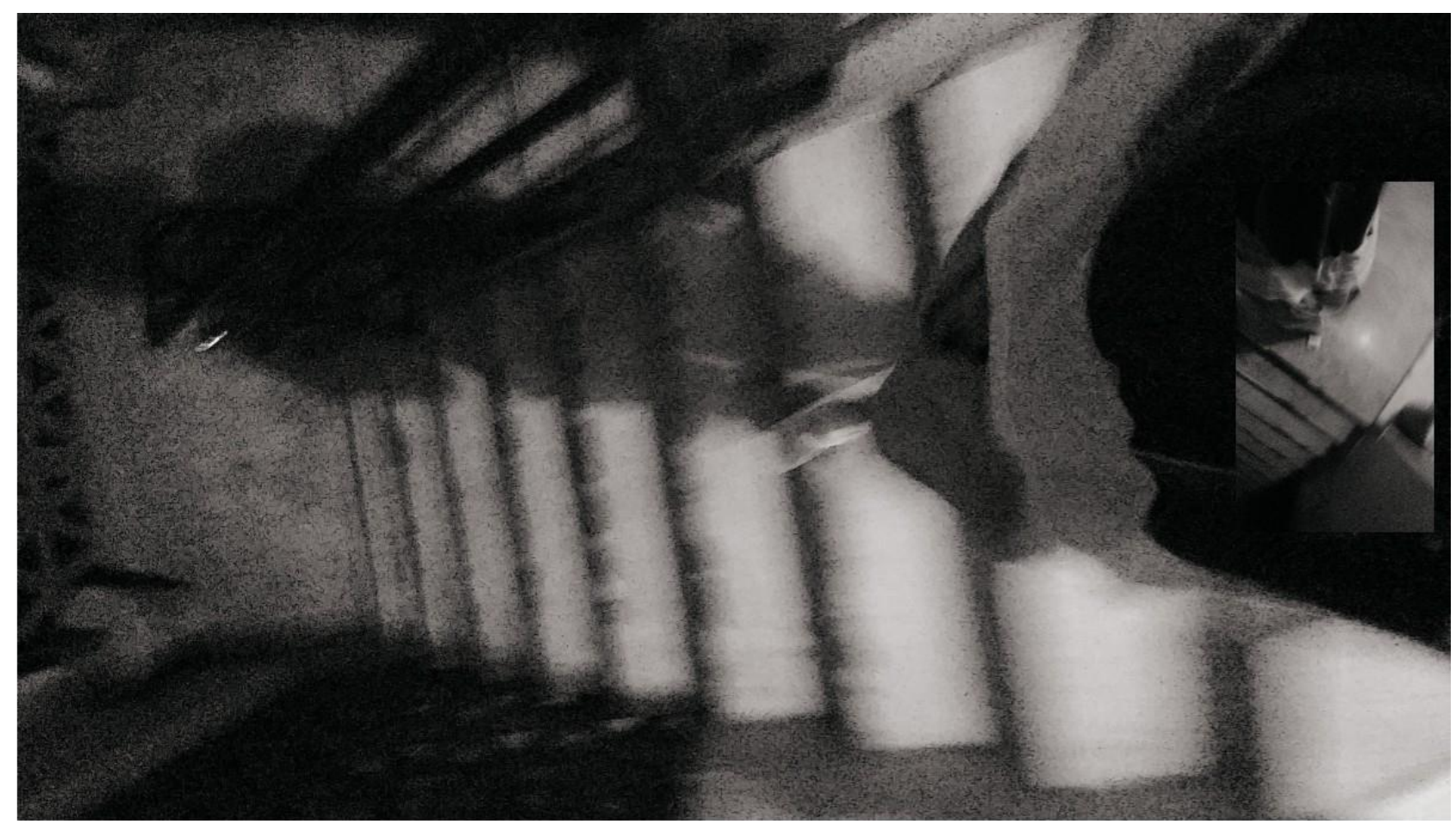

Intentional Experience. Experience in general 

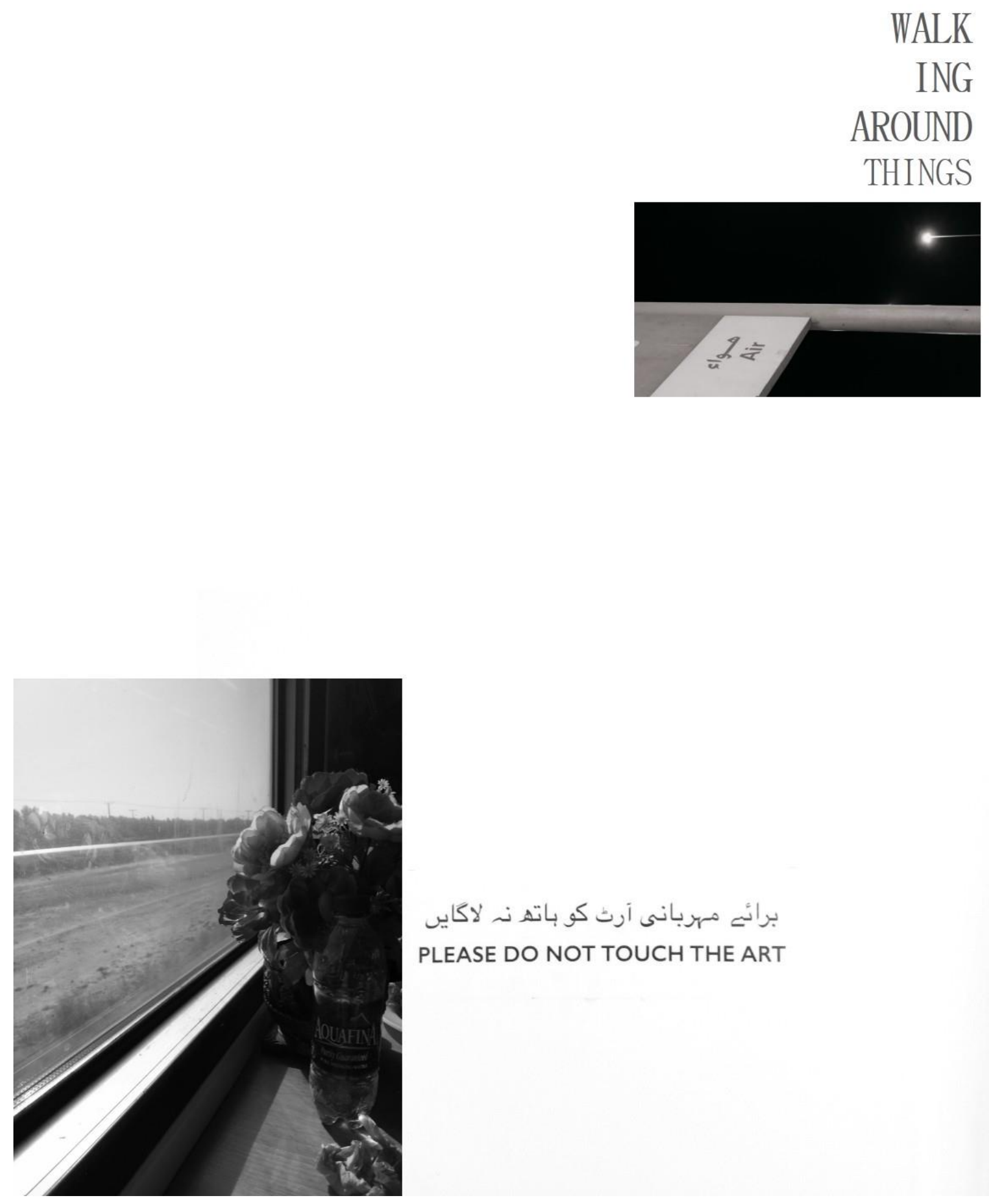

برائَ مهربانى آرث كو باته نـ لاكايي

PLEASE DO NOT TOUCH THE ART

\section{Conclusion}

The city can have a myriad of contexts, a range of meanings as opposed to its one. Through this research I have become more aware of the tangible and intangible qualities of a city. I found photography to be the medium of my translation, one that had the power to change perception and perceptual space or the perception of a space. The surroundings led me to this attempt to understand how the thread of continuity and order is maintained in a continuously shifting sense of a city, what part of identity do people manage to hold on to, do space and objects 
define their conscious and unconscious presence. The work above as all part of an ongoing process, with a lot more photographs, text and physical interventions. I end this with more questions than answers, in a research led studio practice that seems to loom on larger upon me, hoping for more clarity as the years go by.

\section{References}

Beste, A. (2016, May 18). MCA Talk: The City Between Image and Fact. YouTube Channel - Museum of Contemporary Art Chicago. Chicago.

From Picasso to Ed Rusha: the use of text in visual art explained. (2018, July 31). Retrieved July 18, 2018

Goffman, E. (1959). The Presentation of Self in Everyday Life. Anchor Books.

Jacobs, J. (1992). The Death and Life of Great American Cities. Vintage.

Jafri, S. (2017). International Day for Monuments and Sites - Monuments and Sites: Retelling, Reconnecting, Reliving. Lahore: IAC.

Lynch, K. (1960). The Image of the City. Massachusetts: MIT Press.

Wurman, R. (1971). Making the City Observable. Mit Press. 